was similar to that of horse methæmoglobin, except that the absorption in the green was more pronounced. The small thickness of the crystals rendered examination in any other than the $c$ plane impracticable, but made it possible, on the other hand, to get spectra which were bright enough to photograph (Fig. 2). The photographs taken on the panchromatic plate show the change in width and strength of the band in the red, while those on the isochromatic plate illustrate the variation of the general absorption in the green and blue.

In needles of horse oxyhomoglobin, both the characteristic absorption bands in the green and in the yellow were strong and sharp when the vibration direction was perpendicular to the needle axis, and faded out when the vibration direction was parallel to it.

In horse methæmoglobin the absence of pleochroism in the $a$ plane and the sharpness of the band in the red in combination with the high general absorption in the green and blue in vibration directions parallel to $\beta$ and $\gamma$, indicate that the four hæme groups contained in one molecule are approximately parallel to each other and lie in the $a$ plane. This orientation also agrees with the positions of the high refractive indices. It was shown by the effect of acid on the crystals that the absorption must be due to dipoles induced in the hæme groups themselves, since the relation of the absorption bands to the vibration directions in the crystal remained unchanged even after the hæme groups had become detached from the globin component and the position of the absorption band had shifted to that corresponding to free ferrihæmatin chloride.

In drawing these conclusions it has been assumed that the coefficient of absorption is high when the electrical vibration of the polarized light is parallel to the hæme groups and low in any other direction. This assumption appears justified, since the strong colouring power of the hæmatin complex is understood to be due to its large planar system of conjugated double bonds, and dipoles induced in this system must reach their maximum value when the electrical vibration of the light is parallel to the plane containing the double bonds. This relation between pleochroism and molecular orientation has been established by Bernal and others, who applied it to the structure analysis of crystals possessing layers of flat molecules or chains ${ }^{3}$.

$\mathrm{X}$-ray data showed that the four hæme groups in methæmoglobin must be arranged in pairs related by twofold axis ${ }^{2}$. Their parallelism now indicates that they may lie at the corners of a square as suggested by Pauling 4 . In horse oxyhæmoglobin their arrangement appears to be the same as in methæmoglobin, since its crystals belong to the same system, have similar axial ratios and exhibit the same type of pleochroism ${ }^{1}$. According to Haurowitz ${ }^{5}$, reduced horse hæmoglobin crystallizes in the form of hexagonal plates, which on contact with oxygen change spontaneously into the monoclinic needles of oxyhæmoglobin. This change of symmetry indicates that a rearrangement of the hæme groups may take place on reduction.

I have to thank Dr. G. S. Adair for his collaboration in preparing the crystals, Prof. J. D. Bernal for suggesting this research, and Prof. D. Keilin and Dr. E. F. Hartree for much practical help and advice.

Summary. The absorption spectra of single crystals of hæmoglobin in polarized light have been examined. In met- and oxyhæmoglobin of horse and in methæmoglobin of sheep, the width and strength of the absorption bands was dependent on the vibration direction of the polarized light. The results indicate an approximate parallelism of the four hæme groups in the met- and oxyhæmoglobin molecule.

\footnotetext{
"Reichert and Brown, "The Crystallography of the Hæmoglobins" (Carnegie Inst., Washington, 1909).

" Bernal, Fankuchen and Perutz, Nature, 141, 523 (1938).

${ }^{3}$ Bernal and Crowfoot, Trans. Farad. Soc., 29, 1032 (1933). Taylor, Z. Kristall., A, 93, 151 (1936). Wells, Proc. Roy. Soc., A, 167 172 (1938).

${ }^{4}$ Proc. Nat. Acad. Sei., 21, 186 (1935).

${ }^{5}$ Z. physiol. Chem., 254, 266 (1938).
}

\title{
Chemistry and its Applications in Modern Life
}

\section{Meeting of the American Chemical Society}

\begin{abstract}
A MEETING of the American Chemical Society was held early in April at Baltimore, when many papers of topical interest were presented. Grouping the papers by subjects, it is possible to indicate some of the more striking advances which were recorded.

One group of papers dealt with vitamins and hormones. The close relation between vitamin $A$ and vitamin $\mathbf{A}_{2}$ (occurring in visual purple and in the livers of freshwater fish) has been established by distillation under very low pressure. Papers on the content of vitamin $\mathrm{C}$ in various vegetables and its changes on boiling and storage showed, among other things, that loss on boiling is reduced by putting a cover on the vessel so as to exclude air. A covered aluminium vessel was better than covered glass or enamel vessels unless sodium carbonate was added to the green vegetable, in which case the loss was greater with the aluminium vessel. Contrary to the general belief that citrus fruits and tomatoes are the
\end{abstract}

richest sources of the antiscorbutic vitamin C, it has been found that freshly picked parsley, broccoli, kale and cauliflower contain two to three times as much vitamin $\mathbf{C}$ as citrus fruits. Vitamin A concentrates were found not to lower the fat content of milk produced by cows fed on them, whilst fish oils tended to lower the fat content.

Whey has been shown to be a valuable source of vitamins and vitamin products, including all the known water-soluble vitamins, the fat-soluble provitamin $D$, vitamin $K$ (pro-thrombin), vitamin $E$, œstrin and vitamin $\mathrm{B}_{2}$ or $\mathrm{G}$. The importance of whey as an adjunct to feeding animals was shown experimentally. The use of whey products in human foods, especially in bakery goods and confectionery, has also been the object of research.

Zinc insulin crystals have been widely used in the treatment of diabetes in the United States and Canada. The chemistry of the visual systems and of the adrenal cortical hormones has been actively 
worked upon. Adrenal gland extract has been shown to contain at least twenty-four different substances allied to cholesterol, bile acids and the sex hormones, one of them being progesterone, the hormone produced by the corpus luteum of the ovary. The biological functions of the pituitary gland have been more closely investigated and the results correct many views formerly held in this field. For example, it is now known that certain physiological effects claimed to be due to different separate anterior pituitary principles can be attributed to one principle, exerting these effects in ways depending on its mode of administration. Doubt has been cast on the assumption that the thyroid stimulating effect of the pituitary is produced by a separate principle acting on the thyroid gland only.

Another group of papers dealt with cellulose and cellulose products. The purification and utilization of wood cellulose have been investigated, and the suitability of various kinds of woods studied. The main object in view was the production of a cellulose suitable for the production of viscose, since this accounts for 80 per cent of the wood-pulp cellulose used for chemical purposes. An interesting paper dealt with the use of the whole cotton plant with ripe bolls for the production of cellulose; the oil is first extracted from the seeds of the whole ground plant and the cellulose isolated from the residue.

Petroleum and its products received attention from several points of view. The dehydrogenation of petroleum by cracking has led to an increased supply of reactive olefines used in the synthesis of iso-octane, ketones, organic derivatives and plastics. The production of aviation fuels by high-pressure hydrogenation is increasing, one of the principal blending agents being iso-octane. New catalysts have been developed. The superior fuels now available have enabled engine manufacturers to build engines capable of greater power output per unit weight. The stabilization of petrols by small quantities of organic compounds known as deactivators, which prevent oxidation, is an important advance.

Casein products and the utilization of lactic acid provided topics of interest from the point of view of plastics, including polymethylacrylate from lactic acid. A wool-like fibre is made from casein by dissolving in alkali solution and forcing under pressure into a solution containing acid, formaldehyde and either salts or sugars. The fibre is then treated with oils and other substances to increase its flexibility and strength and to bleach it, and is cut into staple lengths, carded and spun into yarn. It may be dyed and laundered in the same way as wool. It shrinks less than wool but has poor tensile strength, especially when wet.

Resins, shellac varnishes, house paints, organic sulphur compounds, and other topics of technical interest also featured in the papers. Of more academic interest were papers on exchange reactions of heavy isotopes of oxygen and nitrogen. The use of aspartic acid as an anticoagulant for blood is of medical interest, as it prevents clotting in the circulation. Aspartic acid is a natural component of plant and animal tissues; it is used as the sodium salt injected intramuscularly, but further studies are to be made of the possible injurious effects on the kidney such as are noted with other anticoagulants. It is stated that, of the long list of amino-acids formed from proteins in digestion, only two have any appreciable effect in preventing clotting, namely, cysteine and aspartic acid, and aspartic acid is much more potent.

\section{Science News a Century Ago}

\section{The Zoological Society}

THE anniversary meeting of the Zoological Society was held on April 29, 1839, Lord Braybrooke being in the chair, when the reports for the year were submitted. That by the auditors stated that the receipts had been $£ 14,0942 s .9 d$. and the expenditure 112,588 12s. 1d. Among the assets of the Society was the farm at Kingston valued at $£ 11,000$. In the report of the Council it was stated that steps were being taken to reduce greatly the permanent expenditure. In 1837 salaries were $£ 3,548$, but for the coming year that would be reduced to $£ 2,916$. An increase had taken place in the cost of provisions due to an increase in the number of animals, "and amongst other circumstances to the growth of the larger elephant". There were 3,010 members of the Society, 38 candidates for election and 126 corresponding members. The Museum contained 760 mammalia, 5,230 birds, 1,000 reptiles, 1,170 fishes and 83 mounted skeletons.

\section{Jupiter's Satellites}

UNDER the above title, the Athenceum of May 4, 1839, said, "An irregularity in the first satellite of Jupiter has for some time attracted the attention of M. Boguslawski, the director of the observatory at Breslau. $\mathrm{He}$ observed it on the 14th of April 1838, and on the 1st of May he made further observations, when he found that its lustre, which, generally speaking, is greater than that of the second, appears to be much weaker when it quits the disc of the planet after its passage across, especially when its shadow is seen upon Jupiter. By means of the heliometer he kept the second satellite always by the side of the first, and at the same distance from the disc, in order to ascertain if the light of the planet were the cause of the diminution. For several hours after leaving the disc at $12 \mathrm{~h} .54^{\prime} 26 \cdot 2^{\prime \prime}$ sidereal time, the first satellite was evidently paler than the second; it then slowly began to resume its light, but which at $15 \mathrm{~h} .18^{\prime}$ had not yet attained that of the second. The next day it had quite resumed its lustre, and again surpassed that of the second".

Palon Heinrich Ludwig von Boguslawski was born at Magdeburg in 1789 and died in 1851. He was well known for his observations of comets and published an astronomical year-book, entitled "Uranos".

\section{Further Discoveries by $\mathrm{M}$. Lartet}

Iv its column of Miscellanea, the Athenceum of May 4, 1839, said : "The indefatigable M. Lartet, of whose labours we have so often spoken, announced the discovery of two fossil Carnivora, one of which appears to constitute a sub-genus; intermediate between the badger and the otter, and the second approaching to the dog, differing but little from that gigantic fossil which he has described under the name of Amphicyon. $\mathrm{He}$ is of the opinion that the latter is the same animal as that of which some remains were found at Epelsheim, and which constitute the Agnotherium of M. Kaup. There are a considerable number of fossil mammiferæ found on the border of the Rhine, which appear to be identical with those which are daily brought to light at the foot of the Pyrennees. These affinities are the more interesting, because the intermediate countries, Auvergne, for instance, possessed very different races of animals." 